Chapter 24

\title{
The Role of PARP Activation in Prostate Cancer
}

\author{
Luis A. Espinoza \\ Additional information is available at the end of the chapter \\ http://dx.doi.org/10.5772/53297
}

\section{Introduction}

Prostate cancer is the most commonly diagnosed cancer in men and the second leading cause of cancer related mortality. Localized prostate cancer is treated by either radical prostatectomy or radiotherapy. Low levels of testosterone have been associated with prostate cancer progression. These tumor presented advanced tumor stage, high Gleason scores, and had significantly worse overall survival rate $[1,2]$. Indeed, intraprostatic dihydrotestosterone (DHT) were consistently reduced in patients with high-grade (Gleason scores of 7 to 10) compared to patients diagnosed with low grade tumors (Gleason scores of 6 or less) [3]. Prostate cancer usually is treated using chemotherapy, radiotherapy, or surgery. For advanced prostate cancer, hormonal therapy is currently used as the standard treatment, however; these tumors develop and aggressive phenotype and become hormone-independent (hormone-refractory) (HRPC) that is resistant to chemotherapy or radiotherapy and metastasizes to lymph nodes and bone [4].

Although prostate cancer is the most common cancer in Caucasians, the risk factors associated with increased prostate cancer incidences include mainly in those individuals with subSaharan African ancestry, with African-American men having the highest reported incidence rates of all ethnic groups in the United States $(239.8$ cases/100,000) $[5,6]$. Furthermore, mortality from prostate cancer following surgery is nearly two-fold higher in AfricanAmerican men $(56.3 / 100,000)$ succumbing to the disease compared to white men (23.9/100,000) [7-9]. Little is currently know whether the type of factors (biological, diet, racial, or lifestyle) that may play a influence role in the increased prostate cancer incidence in this population. The high mortality in death from prostate cancer is generally due to metastatic disease that results from resistance to the treatments described above. Since rates of prostate cancer in the U.S. are 60 percent higher among African-American men, and their mortality rate are two-and-a-half times that of Caucasian men [10, 11], identifying the mechanisms that support indolent against aggressive disease is an important area of research. 
Prostate cancer cells that survive chemotherapy or radiation treatment clearly indicate that may be able to repair most of the radiation-induced DNA breaks. Indeed, different prostate cancer cell lines have shown a very efficient DNA repair system in which DNA damage can be removed $[4,12]$. Also, there is the possibility that genetic instability occurring in those cancer cells with unrepaired or misrepaired DNA damage might increase prostate cancer aggressiveness. In this regard, there is an increasing interest in the utilization of PARP inhibitors as a strategy for improving cancer therapy [13]. PARP is a nuclear enzyme that plays active roles in DNA repair, DNA replication, and cell death, in response to diverse forms of stimuli from normal metabolic processes, as well as environmental factors [14, 15]. This enzyme binds nonspecifically to DNA breaks and catalyzes the poly(ADP-ribosyl)ation of various nuclear proteins utilizing $\mathrm{NAD}^{+}$as a substrate, leading to chromatin decondensation that allows the repair process for DNA damage.

Overexpression of PAPR1 has been described in a variety of tumor cell lines, which was associated with malignant progression [16]. PARP-1 high levels has also been found in malignant lymphoma cells compared to normal lymph nodes [16], adjacent non-tumor tissues, or hyperplastic polyps [17]. High levels of PARP-1 also showed high correlation with poor prognosis in early breast cancer. In this type of cancer, PARP-1 was indicated to be the major component of tumor cells response to DNA damage and a key player in maintaining their genetic stability. Augmented expression of PARP-1 was also observed in moderate differentiate hepatocellular carcinomas (HCC) [18]. In addition, poly(ADP-ribosyl)ation was consistently increased in HCC [19], colon carcinomas [20], cervical cancer [21], and melanoma and basal cell carcinoma [22]. More recent findings have found that overexpression of PARP-1 appear to be related with prostate cancer progression, and also considered as a potential independent predictor of aggressiveness among the clinicopathological features related to this type of tumor [23].

Prostate tumors that initially respond to standard chemotherapy often recur; with selective outgrowth of tumor cell subpopulations that are resistant not only to the original chemotherapeutic agent, but also to other therapeutics. Therefore, the promising results of PARP inhibitors in treating advanced states of prostate cancer provide new avenues for effective treatment of this deadly disease. This chapter focuses on PARP-1 as a potential target to improve the breadth and effectiveness of prostate cancer treatment.

\section{The biological roles of PARP-1}

PARP-1 is a nuclear protein that catalyzes the covalent long chain poly(ADP-ribosyl)ation of a variety of nuclear proteins utilizing $\beta$-nicotinamide adenine dinucleotide $\left(\mathrm{NAD}^{+}\right)$as a substrate, with PARP-1 itself being the major target of modifications [24, 25]. Moreover, many other nuclear DNA binding proteins are also modified. PARP-1 is only activated when bound to single- or double-stranded DNA ends via its two zinc fingers, which recognize DNA breaks independent of the DNA sequence $[14,15,25]$ (Table 1). The active protein catalyzes a sequential transfer reaction of ADP-ribose units from $\mathrm{NAD}^{+}$to various nuclear proteins, forming a protein-bound polymer of ADP-ribose units [24]. 


\begin{tabular}{ll}
\hline Agents that activatePARP-1 & Events inducing DNA breaks \\
\hline Alkilating agents & Aging \\
Apoptosis inducers & Chromosomal alterations \\
Asbestos & Differentiation \\
Hydrogen peroxide $\left(\mathrm{H}_{2} \mathrm{O}_{2}\right)$ & Gene expression \\
lonizing radiation & Genetic instability \\
Oxidising agents & DNA replication \\
Nitrosative stress & Inflammation \\
Topoisomerase inhibitors & Necrosis \\
& Programming cell death \\
\hline
\end{tabular}

Table 1. List of events that promote DNA breaks and PARP-1 activation

Since PARP-1 activation is strictly proportional to the number of DNA breaks, its activity is strictly proportional to the number of DNA breaks in vivo or in vitro, and it is particularly inactive in the absence of DNA breaks $[15,25,26]$. DNA damage can occur during DNA replication or as consequence of exposure of cells to different types of genotoxic agents (Table 1). One of the earliest cellular events that follow this phenomenon is the poly(ADP-ribosyl)ation of PARP-1 and an array of DNA binding proteins that are localized predominantly adjacent to the DNA strand breaks, resulting in polymers adjacent to DNA breaks and in the recruitment of additional proteins that are essential in BER/SSBR [27, 28].The covalent poly(ADP-ribosyl)ation of nuclear DNA-binding proteins in eukaryotes is a phenomena that contributes to various physiologic and pathophysiologic events associated with DNA strand breakage, repair of DNA damage, and apoptosis [15, 29-32]. Detailed studies have demonstrated that in addition to its accessory role in DNA repair, PARP-1 also plays regulatory roles in other nuclear processes, including DNA replication and the regulation of transcription, as a longevity assurance factor associated with genome stability, and in redox signaling [26] (Table 2). In addition, the post-translational modifications reaction in which poly(ADPribosyl)ation is involved during post-translational reactions is mainly related to the modulation of chromatin and function in DNA-damaged and apoptotic cells [32, 33]. The nuclear protein substrates of PARP-1 include histones, DNA topoisomerases I and II [34, 35], SV40 large T antigen [36], DNA polymerases $\alpha$ and $\delta$, proliferating cell nuclear antigen (PCNA), and several proteins that are components of the DNA synthesome [35].

The interaction of PARP-1 with components of the base excision repair (BER) complex such as DNA ligase III, DNA pol $\beta$, and XRCC1 [37-40], suggested that PARP-1 may have protective function in the BER repair process. PARP-1 has also been shown to interact with a number of transcription factors (Table 3), including AP-2 [41], CXC ligand [41], E2F-1 [32], NF- $\mathrm{B}$ [42], MYB [43], Oct-1 [44], PC3/topoisomerase-I [45], SP-1, TEF-1 [46], and YY1 [47]. Although ADP-ribosylation has been indicated as the main mechanism by which PARP-1 modulates most of these transcription factors, consistent reports in which PARP-1 inhibitors 
and the downstream effects of NF- $\kappa \mathrm{B}$ pathways were analyzed [48] have argued against the requirement of PARP-1 as a critical co-activator of NF- $\kappa B[49,50]$.

\begin{tabular}{l} 
Roles of PARP in cellular and molecular processes \\
\hline Control of cell cycle \\
Cell differentiation \\
Cell death \\
Chromatin architecture \\
DNA repair \\
Redox signaling \\
Transcription
\end{tabular}

Table 2. List of the roles PARP-1 plays in molecular and cellular processes.

The dual roles of PARP-1 in different nuclear processes are based in on the levels of the substrate $\mathrm{NAD}^{+}$and the presence of PARP-activating DNA breaks. Indeed, physical interaction of PARP-1 with DNA polymerase $\alpha$ occurs in the absence of $\mathrm{NAD}^{+}$activates polymerase $\alpha$ [51], while addition of $\mathrm{NAD}^{+}$to the DNA replication complex inhibits polymerase $\alpha$ catalytic activity [52]. Although in the absence of $\mathrm{NAD}^{+}, \mathrm{PARP}-1$ interacts with different transcription factors to enhance activator-dependent transcription, the presence of $\mathrm{NAD}^{+}$and consequent PARP-1 activation represses transcription, presumably by poly(ADP-ribosyl)ation of a series of transcription factors [53]. Thus for example, in the absence of NAD, PARP-1 enhances activator-dependent transcription by interacting with RNA polymerase II-associated factors [53], binds to the transcription enhancer factor 1 (TEF1) and enhances muscle-specific gene transcription [46], and transcription factor AP-2 to co-activate AP-2-mediated transcription [41]. Meanwhile, PARP-1 depletion silences the activation of a number of transcription factors, preventing the formation of active transcription complexes and binding to their respective DNA consensus sequences [54].

In most of the cases, the poly(ADP-ribosyl)ation modification of proteins inhibits their affinity for DNA-binding as a result of the electrostatic repulsion between the negatively charged DNA and long chain of approximately 200 units of poly(ADP-ribose) (PAR) [24, 25]. Although unmodified PARP-1 binds tightly to DNA ends, interfering with the repair machinery, the prolonged poly(ADP-ribosyl)ation automodification of PARP-1 itself is essential to modulate its binding to DNA ends during the repair process $[55,56]$. The decrease in DNAbinding affinity caused by electrostatic repulsion between DNA and poly(ADP-ribose) (PAR) as a result of the pos-translational modification may explain the reduction on the catalytic activity of some DNA-binding proteins [57, 58]. Modification of other nuclear proteins such as nucleosomal proteins may also allow the access of various replicative and repair enzymes that bind specifically to those regions of the DNA containing strand breaks $[59,60]$. 


\begin{tabular}{ll}
\hline Function & Acceptor proteins \\
\hline Cell cycle regulation & p53 \\
PCNA & Histone \\
Chromatin structure & HGM \\
& Lamins \\
& LMG proteins \\
& DNA polymerase a \\
& DNA polymerase $\beta$ \\
DNA metabolism & DNAS1L3 \\
& Endonuclease \\
& PARP-1 \\
& Poly(ADP-ribose) synthetase \\
Topoisomerase I & Topoisomerase II \\
& XRCC1 \\
& Tankyrase-1 \\
Telomeric repeat binding factor-1 \\
\hline
\end{tabular}

Table 3. List of acceptor proteins for poly(DP-ribose).

The elevated levels of sister chromatid exchanges (SCE) found in PARP-1 knockout mice have been associated with increased genomic instability [61, 62]. Similar events have been reported in splenocytes and fibroblasts isolated from PARP-1 $1^{--}$animals, which also exhibited signaling abnormalities, apoptosis, proliferation, and defects in DNA repair [62, 63]. Accordingly, animals carrying deletion of the exon 1 [64], exon 2 [61], and exon 4 [62], neither evidenced PARP-1 protein nor exhibited signals of poly(ADP-ribosyl)ation. It was also described that thymocytes derived from PARP-1 knockout mice showed a delayed recovery after exposure to gamma-radiation [61]. Also, PARP-1 inhibition/deletion does not alter key cellular events such as apoptosis, DNA replication, and differentiation in cells derived from these mice; however, some evidence has indicated that PARP-1 has supportive roles in all these processes. Indeed, derived PARP-1 deficient cells showed pronounced effects on some of these events that are not observed in wild type cells $[65,66]$.

\section{Involvement of PARP-1 in prostate cancer progression}

Localized prostate tumors are treated by either radical prostatectomy or radiotherapy and usually survive many years [67]. For aggressive prostate cancer, hormonal therapy is the 
standard treatment however; a significant amount (approximately 30\%) of these tumors become hormone-independent (hormone-refractory) [11]. Prostate cancer cells that survive chemotherapy or radiation treatment may be capable to repair most radiation-induced DNA breaks. This is supported by evidence showing both in androgen dependent and independent prostate cancer cell lines in which the EGFR-ERK signaling pathway up-regulates a series of DNA repair proteins, including ERCC1, XPC, and XRCC1, in response to DNA damage [68]. These proteins efficiently repaired the damaged DNA, and enhanced the survival of cells following exposure to genotoxics $[68,69]$. The activation of PARP-1 in the presence of DNA breaks consistently promotes the recruitment of XRCC1 and the physical interaction of XRCC1 with PARP-1 has been indicated as an efficient process to repair DNA breaks in a coordinated manner [39]. However, it needs to be taken into account that genetic instability may occur in those cells with unrepaired or misrepaired DNA damage. In this respect, the LNCaP prostate cancer cell line, an androgen-responsive is a good model because undergoes growth arrest, but not apoptosis after androgen deprivation, and it is also highly resistant to radiation-induced cell death $[70,71]$.

Given that activation of PARP-1 is absolutely dependent on DNA strand breaks [15, 26], the substantial poly(ADP-ribosyl)ation modification of PARP-1 detected during early apoptosis in LNCaP cells was consistent with the DNA damage induced by Phenoxodiol, a synthetic analogue of Genistein [72]. Although the level of PARP-1 activation and its subsequent cleavage in LNCaP cells after Phenoxodiol exposure was exhibited in a time dependent manner, the poly(ADP-ribosyl)ation automodification of PARP-1 activation during the early stages of Phenoxodiol-induced apoptosis may thus be required for progression through the death program [72]. In this respect, subsequent cleavage of PARP-1 may have prevented the depletion of $\mathrm{NAD}^{+}$and ATP, which are needed for later steps in apoptosis [73]. However, the possibility that inhibition of the topoisomerase II activity may have caused DNA damage in cells exposed to Phenoxodiol, a well-known topoisomerase II poison, was not excluded [74]. As a matter of fact, activation of PARP-1 has also been detected in apoptotic cells exposed to different antineoplastic agents, such as adriamycin, alkylating agents, cisplatin, mitomycin C, radiation, and topoisomerase inhibitors [75].

A combined treatment of isoflavones and curcumin had a potent inhibitory effect on cellular proliferation of LNCaP cells [76]. The effects associated with this treatment were the enhanced phosphorylation of some nuclear proteins, such as ATM and Chk2 when compared to the effects of cells treated with curcumin alone. Similar effects were observed in the histone H2AX and p53. Interesting, curcumin also inhibited the proliferative effects of the dihydrotestosterone (DHT), a stimulator of prostate growth [3]. The augmented levels of testosterone consistently induced activation of the DNA damage response (DDR) pathways in response to curcumin treatment by promoting the phosphorylation of $\mathrm{CHK}, \mathrm{H} 2 \mathrm{AX}$ and p53. This approach also induced the proteolytic cleavage of PARP-1, suggesting that activation of the DDR by polyphenols might have a suppress effect on malignant transformation, while a combined therapy of testosterone and curcumin may enhances apoptosis by promoting the release of pro-apoptotic factors, restricting thus prostate cancer progression. 
To determine the signaling pathways that are induced by radiation-induced PARP-1 activation, two prostate cancer cell lines LNCaP and DU145, which express different levels of EGFR, were exposed to ionizing radiation and EGF [77]. Although the radiosensitivity was much more evident in LNCaP cells, the radiation treatment consistently reduced the clonogenic survival in both cell lines. The addition of EFG or PD184352, a MEK 1/2 inhibitor, had any significant impact on the killing of the cancer prostate cells. In contrast, PJ34, a potent inhibitor of PARP-1 [78], caused a growth arrest and markedly reduced cell death in both cell lines [77]. In support of these data, poly ADP-ribosylation of PARP-1 was also evident in LNCaP and DU145 cells after irradiation or exposure to EGF. These results are supported by findings linking EGF expression to human prostate cancer development [79, 80], the high levels of EGF secreted by LNCaP and DU145 cell lines [81, 82], as well as the enhanced invasive capacity that EGF exert on another human prostate cancer cell line (PC-3) [83]. Although the reduction of cell death was evident in cells exposed to PJ34 and EGF; however, an opposite effect was observed when PD184352 or the inhibitor of EGF receptor kinase, AG1478, alone was added to the cultures. When the same experimental approaches were applied to PARP-1-depleted cells, expression of poly ADP-ribose production was practically eliminated [78]. This study indicated that PARP-1 activation in both cell lines is linked to the EGF-ERK signaling pathway, which may be critical for the poly ADP-ribosylation and regulation of $\mathrm{NAD}^{+}$content following irradiation, and may also be critical for cell survival after treatment for prostate cancer.

Similar apoptotic effects including, annexin-V binding and TUNEL staining, loss of mitochondrial membrane potential the release of cytochrome c, activation of caspase- 3 , and increase of PARP-1 cleavage were observed in PC-3 cells treated with b-caryophyllene oxide (CPO), wortmannin, and the AKT inhibitor IV [84]. Downregulation of several proteins that are part of the PI3K/AKT/mTOR/S6K1 signaling cascade and ROS-mediate MAPKs activation were also identified, which strongly suggested that multiple cascades are involved in cell survival and proliferation of prostate cancer cells. Accordingly, LNCaP cells exposed to isochaihulactone, a lignin with proved antitumor activity in vitro and in vivo models [85], evidenced the involvement of the JNK pathway as a potential target for the activation of proteases that are crucial in the induction of caspase-3 activation and PARP-1 cleavage, hallmarks of apoptosis cell death.

\section{The relationship between the expression of PARP-1 and p53 in prostate cancer}

It is well known that the tumor suppressor gene p53 is a key player in controlling the genetic stability in breast tumor cells [86]. More recently, it was reported that inhibition of PARP-1 by veliparib enhances DNA damage in BRCA-proficient cancer cells, a process that appears to be regulated by $\mathrm{p} 53$. Although a diverse response was observed in p53-mutant or -null cells, the veliparib and topotecan combination enhanced DNA damage response and cell death in these type of cells [87]. Similarly, treatment of LNCaP cells to a new ligan isochaihulactone, a proved inhibitor of cell proliferation and effective inducer of apoptosis in a 
variety of cancer cell lines, enhanced PARP-1 cleavage and increased levels of p53 in those cells that become irreversible committed to cell death [88].

Considering that PARP-1 is thought to be an important modulator of p53 [89], either by covalent modification or by non-covalent binding of poly(ADP-ribose) on specific domains of p53, which alter its DNA binding functions [47], the binding of p53 to DNA damage promotes activation of downstream signal cascades, leading to cell cycle arrest and apoptosis. A recent report have demonstrated the efficacy of a novel CDK1, CDK2 inhibitor, dansylated VMY-1-103, in inhibiting Erb-2/Erb-3/heregulin-induced cell proliferation in LNCaP cells. Apoptosis via decreased mitochondrial membrane polarity, induction of p53 phosphorylation, caspase- 3 activation, and PARP-1 cleavage in these prostatic tumor cells, were also among the most relevant findings [90]. The stability of p53 as evidenced by an increase of p53 content is crucial for blocking cell cycle progression or for initiating cell death apoptosis in response to DNA damage $[91,92]$. However, it cannot be excluded that other DNA repair proteins can also bind simultaneously to the damaged site and may activate alternative signaling pathways in response to genotoxic insults. The determinant of which of these mechanisms is chosen can be dependent on the magnitude of damage to the DNA.

Although p53 and PARP-1 are both damage sensor proteins and can be functionally activated by DNA damage $[92,93]$, evidence indicated that PARP-1 is not essential for p53 accumulation induced by DNA damage. However, PARP-1 appear to be required for the appropriate response of p53 to DNA damage [89], including its rapid and enhanced protein expression [91]. In this respect, immunoblotting analysis with antibodies against p53 were able to detect p53 protein in lysates of PARP-1 wild-type cells, but not in PARP-1 deficient cell extracts, which suggested that the reduced protein stability of p53 in cells lacking PARP-1 [94]. The functional interaction between p53 and PARP-1 in response to radiation was also reported in a human glioblastoma cell line A-17 treated with 3-aminobenzamide (3$\mathrm{AB})$, a well-known PARP-1 inhibitor. The absence of PARP-1 activity by 3-AB dramatically reduced the radiation-induced expression of the p53 downstream, the p21 gene product. In support to this observation, the gel shift analysis evidenced that 3-AB significantly inhibited the irradiation-activated p53-binding activity to its consensus sequences [95]. Similar results were observed in a (1-methyl-4-phenyl-1,2,3,6-tetrahydropyridine) (MPTP)-induced parkinsonism model in which a heavy poly(ADP-ribosyla)tion modification of p53 reduced the DNA-binding activity of p53 to its consensus sequences [96].

Although the specific findings above described clearly proof that PARP-1 expression is implicated in p53 accumulation and stabilization, this effect is different to that observed in PARP-1 knock out cells exposed to N-methyl-N-nitroso urea (MNU), an alkylating agent, in which p53 is accumulated and its activation is consistently enhanced [97]. The findings in this model suggest that PARP-1 regulating p53-mediated response to genotoxic agents is probably dependent on the type of DNA damage. Accordingly the level of MDM-2 transcript, an important negative regulator of the p53, was not increased after gamma-irradiation; however, an increased in the expression of MDM-2 protein was observed in PARP-1 null cells. The increased levels of MDM-2 may provide an alternative explanation for the reduced accumulation and activation of p53 in PARP-1 null cells. Furthermore, the reduced 
phosphorylation of p53 may also be indicative of a defective activation of the kinases pathways in these cells [97].

Other studies have demonstrated that PARP-1 is dispensable for the repair of DNA doublestrand breaks induced by alkylating agents, UV, and gamma-radiation. In this respect, it was proposed the existence of an alternative radiation-induced pathway involving p53 that may function independently of PARP-1 involvement. Although this alternative mechanism may explain the cytotoxic response detected in PARP-1 null cells after radiation treatment $[61,98]$, this does not necessarily support the significant delay in the transient accumulation of p53 in PARP-1-depleted intestinal epithelial stem cells after exposure to irradiation. Similarly, the survival analysis was markedly reduced in crypts of PARP-1 knockout mice, even at radiation doses that have sublethal effects on wild type animals [65]. These observations extended the crucial role of PARP-1 to stem cells survival after DNA damage in vivo. Indeed, considering the prolonged regenerative capacity of prostate progenitor stem cells may increase their susceptibility to accumulate genetic or epigenetic alterations during their life cycle, the events may be able to increased proliferative rates, decreased cell death, and overall survival advantages over prostate progenitor stem cells, contributing thus to transformation $[6,99-104]$. Along with these studies, PARP-1 inhibition may be a critical component in the treatment of some types of cancer. Additionally, other components of the cell cycle checkpoints such p53 also need to be considered in order to develop an appropriate therapy strategy to avoid relapse.

\section{The prostate cancer microenvironment}

The morphology of a tumor may also influence in the biological responses of cancer cells to a specific therapy. Although most of the reports in cancer therapy utilize monolayer cultures, multicellular aggregates (spheres) are probably more important because reflects the three-dimensional structure for a real-time model representing a tumor, allowing to study the interaction of tumor cells with the microenvironment [105]. The fact that spheroids mimic the tumor microenvironment is also an important tool that may provide more accurate information about the biological and biochemical events occurring in solid tumors [106]. Therefore, the utilization of the spheres assay is an important approach for the in serial in vivo transplantation to verify self-renewal potential.

Although, sphere cells are generated, serially passaged, and maintained in undifferentiated phenotype under appropriate cell culture conditions, they need to be inoculated into animal models to confirm their ability to generate tumor growth [107, 108]. Indeed, substantial differences has been reported in the gene expression signatures on PC3 holoclones compared to parental PC3 cells, which appeared to be consequence of the distinct culture conditions used to growth each cell population [109]. Consistent with these observations, growing conditions also affected the expression of several genes in LNCaP cells [106]. A number of other variables such as the manner in which cells are isolated and the in vitro propagation of these cells before transplantation can cause tumor cells to become more aggressive as a result of 
new acquired mutations, which may affect the outcome of in vivo assays. Another critical parameters are to determine the variation on experimental conditions that may influence frequency estimates and to ensure the best animal model available in order to reproduce the tumor biology as it occurs in humans. For example, the limiting dilution data might be dramatically affected by the duration of data analysis [110] or by modification of xenotransplantation assay in non-obese diabetic severe combined immunodeficient (NOD/SCID) mice [111]. Therefore, a main concern for the application of this methodology is that sometimes, the animal models overstate the biology of cancer formation in humans.

Most of human prostate tumor cells have the ability to form spheres; however, the frequency of cells forming spheres is very heterogeneous across all cell lines. In this regard, the adaptation of tumor cells to non-adherent culture conditions may be a determinant in forming spheres [112]. Also, the holoclone-forming cells, which are smaller than paraclone cells, more adherent, highly clonogenic, and whose progeny forms almost exclusively growing colonies, in prostate cancer specimens with the highest clonogenic potential has been associated with stem cell phenotypes [113]. Of great importance is the fact that large holoclones were also consistently present in prostate cancer cell spheres [109, 114], suggesting that these spheres, which are sustained by tumor initiating cells with stem cell-like features, may have a strong self-renewal and pro-angiogenic capability [115]. These spheres were capable of forming new generations of spheres and retained proliferative capacity as well as clonogenic potential after serial passages [116]. These reports were supported by studies in which a minor subpopulation of spheres propagating cells with stem cell-like properties isolated from a series of prostate cancer models were capable of forming spheres, display significant increase in proliferation potential, initiate xenograft tumors with enhanced capacity, and were more drug resistant compared to monolayer cells [109, 117]. Accordingly, the expression of putative cancer stem cell markers such as ALDH1A1, CD44, CD133, showed strong correlation with prostate tumor progression and metastasis [92, 118, 119], while Nanog induction promoted castration-resistant tumor phenotype and tumor regeneration in the LNCaP cells [120].

There is no doubt that the microenvironment definitely affects the expression of multiples genes that may be more evident in spheroids in which the tumor cell interaction with the extracellular matrix may influence responses to prostate cancer treatment. Thus, the threedimensional system should be included in pre-clinical experimental models to identify in prostate tumors the mechanisms that are related with tumor progression, and those that confer resistant to cancer therapies.

\section{Treating prostate cancer}

Despite recent therapeutic approaches that have significantly increased survival, most prostate aggressive tumors become resistant to current treatment protocols [8, 121]. Prostate cancers that initially respond to standard chemotherapy often recur with selective outgrowth of tumor cell subpopulations that are resistant not only to the original chemotherapeutic 
agents, but also to other therapeutics [122]. Several events are thought to be involved in the dysregulation of pathways, which may activate a different pathway(s) for androgen independence probably through a paracrine androgen-independent pathway, which may explain the multifocality and heterogeneity of prostate cancer and for hormone therapy resistance. Indeed, in a xenograft model, most of androgen-responsive genes that were initially downregulated under conditions of androgen deprivation were later re-expressed in recurrence tumors, indicating failure of androgen-derivation therapy as well as irreversible commitment to tumor progression [123].

The array of genes that comprise the proliferation status may differ in different type of tumors. Evidence has demonstrated that the cell cycle regulation is frequently altered in prostate cancers, in part, by the interplay of oncogenic cascades activation with diverse hormones, growth factors, and cytokines. Moreover, the accumulation of mutations in prostate cancer cells may eventually lead to a more poorly differentiated and aggressive tumor behavior, leading to overall higher rates of progression and worse prognosis, irrespective of the size of the lesion [124-127]. Multiple cellular signaling pathways including, protein kinase B (Akt), mitogen-activated protein kinase (MAPK), the nuclear factor kappa B (NF- $\mathrm{B}$ ), transforming growth factor beta (TGF- $\beta$ ), the vascular endothelial growth factor (VEGF), and the Wnt have been shown to enhance androgen receptor signaling and promote development of hormone-independent/castration-resistance in preclinical models [128, 129]. Moreover, the increased expression of the androgen receptor transcript was critical for tumor cells resistance to anti-androgen therapy [75]. In this regard, inhibitors of cell cycle regulatory proteins has become an area of increased interest in targeting both cancer cells per se and a subpopulation of stem cell-like that initiates and maintains tumor growth, metastasis, and resistance to therapy [130].

Recently, we have demonstrated that Phenoxodiol induces DNA damage in different types of prostate cancer cell lines (DU145, LNCaP, and PC3), leading to the activation and cleavage of PARP-1 as well as the onset of the cell death program [72]. Interesting, the expression of PARP-1 is highly expressed in LNCaP cells before and after treatment with $\mathrm{H}_{2} \mathrm{O}_{2}$ [131] . Also accompanying Phenoxodiol-induced cell death we observed a reduction in the availability of $\mathrm{NAD}^{+}$, which potentially compromises ATP production via glycolysis [132]. A major component of the injury is the alteration of membrane permeability caused by decreased activity of ATP-dependent ionic pumps [133]. Massive NAD ${ }^{+}$depletion is lethal in cells that divide rapidly and have a high-energy requirement. Since the three prostate cancer cell lines, LNCaP, PC3, and DU145 have high metastatic potential and are very resistance to several antitumoral drugs and radiation-induced apoptosis, the fact that this synthetic analogue of Genistein induces death in this tumor type, strongly suggested that this synthetic drug may be a useful treatment for metastatic prostate tumors [72]. A recent study has reported that decreased PSA production and the expression of the androgen receptor in LNCaP cells were observed following a combined treatment with curcumin and isoflavones. Similarly, modulation of PSA levels was observed in a cohort of patients that received prostate biopsies [134]. Finally, cannabidol and the synthetic cannabinoid WIN-55,212 were also determinant in inhibit proliferation and cleavage of PARP-1, caspase-3, as well as activation of 
phosphatases, and pro-apoptotic phosphatase on LNCaP cells. These compounds also exhibited antitumorigenic activity against different types of tumors and are now being tested in clinical trials for the treatment of brain tumors $[135,136]$. The modulation of specific phosphatases in the LNCaP cell line suggested the potential antitumorigenic activity of cannabinoids against the treatment of prostate cancers [137].

\section{Treating prostate cancer with PARP-1 inhibitors}

Recently, the augmented immunodetection of PARP-1 was associated with prostate cancer progression and prediction of biochemical recurrence [138]. Preclinical data also indicated that PARP inhibitors might sensitize cancer cells and potentiate the effects of radiotherapy and chemotherapy. Interesting, inhibition or depletion of PARP-1 by antisense RNA [139], chemical inhibitors [140-142], or by the expression of dominant negative mutants (4-5), promotes genomic instability [143], as revealed by increased DNA strand breakage, gene amplification, micronuclei formation, and sister chromatide exchanges (SCE) in cells exposed to genotoxic agents. Marked SCE frequency has been observed in PARP-1 deficient cell lines and treated with different inhibitors against PARP-1 activity [144]. Depletion of PARP-1 was indicated as the main contribution to genomic alterations that may promote aberrant expression of cell proliferative genes, which may initiate cancer formation or progression. These observations implicate PARP-1 as a guardian of the genome, facilitating DNA repair and protection against DNA recombination by DNA lesion recognition [144] Accordingly, nuclear PARP-1 protein overexpression was associated with poor overall survival in early breast cancer [145]. PARP inhibitors have also been implicated in the modulation of the mechanisms driving apoptotic cell death [146]. Therefore, evidence correlating increased PARP-1 activity with tumor progression has opened a new avenue for the utilization of PARP inhibitors, which may impair the DNA repair machine. These effects may increase sensitivity of prostate tumor cells to DNA damaging agents by improving the efficiency of cancer therapeutics.

An early innovative therapy to treat prostate cancer cells was to enforce the binding of DNA strand breaks to a dominant-negative mutant of the DNA-binding domain of PARP. The recombinant plasmid inhibited the function of PARP-1 and sensitized prostate tumor cells to the lethal effects of ionizing radiation or etoposide (VP-16), with a markedly reduction of cell survival and induction of apoptosis [12]. The pharmacological inhibition of PARP-1 by benzamide pharmacaphores mimics the nicotinamide moiety of $\mathrm{NAD}^{+}$, occupying the donor site [147]. For example, the 3-aminobenzamide (3-AB) was shown to inhibit DNA excision repair and radiosensitize cells to ionizing radiation through impaired DNA repair [148, 149]. $3-\mathrm{AB}$ is also know to inhibit the family of mono(ADP-ribose) transferases, which can produce non-specific effects independent of PARP-1 inhibition (Milam, 1984). Therefore, more potent and highly specific PARP inhibitors that promote oxid radiation sensitizer enhancement ratios have been developed. These new specific compounds (Table 4) are dependent of the cell line and inhibitor tested [150]. Thus, for example ABT-888 (veliparib) inhibited recombinant and intracellular PARP-1 activity and was also toxic to both oxic and hypoxic 
cells. This PARP inhibitor radiosensitize the human prostate carcinoma cell lines DU145 and 22RV1, as evidenced by the reduced clonogenic survival followed by ionizing radiation exposure (Stanley, 2008). Further support for the utilization of ABT-888 in combination therapy comes from studies showing that ABT- 888 enhanced the effects of ionizing radiation in DU145 and PC-3 cells [151]. Interestingly, only PC-3 cells undergo enlarged flat morphology and positive staining for SA- $\beta-\mathrm{Gal}$, and significant overexpression of $\mathrm{p} 21$, hallmarks of cell senescence. These findings were confirmed using PC-3 tumor xenografts in which tumor growth was delayed and presented a senescent phenotype. These results appear to indicate that combined ionizing radiation and PARP inhibition may improve therapeutic response in specific types of prostate cancer.

\begin{tabular}{|c|c|}
\hline Function & Acceptor proteins \\
\hline ABT888 (Veliparib) & $\begin{array}{l}\text { Enhances cell death and tumor growth delay in irradiated cancer } \\
\text { models }\end{array}$ \\
\hline 5-AIQ hydrochloride & $\begin{array}{l}\text { Decreases expression of inflammatory mediators activated by } \\
\text { neutrophils }\end{array}$ \\
\hline 3-Methil-5-AIQ hydrochloride I & $\begin{array}{l}\text { Therapeutic benefits on myocardial infarction, ischaemia-reperfusion } \\
\text { of the liver and kidney, heart transplantation, and acute lung } \\
\text { inflammation }\end{array}$ \\
\hline 3-Aminobenzamide & Potentiate anticancer therapy \\
\hline 4-Amino-1,8-naphthalimide & Radiation sensitizer \\
\hline Benzamide & Neuroprotectant \\
\hline 3-(4-Chlorophenyl)quinoxaline-5-carboxamide & $\begin{array}{l}\text { Ameliorates methamphetamine-induced dopaminergic } \\
\text { neurotoxicity }\end{array}$ \\
\hline $\begin{array}{l}\text { (3,4-dihydro-5-[4-(1-piperidinyl)butoxyl]-1(2H)- } \\
\text { isoquinolinone DPQ }\end{array}$ & $\begin{array}{l}\text { Reduces pre-neoplastic foci, expression of pre-neoplastic markers, } \\
\text { and pro-inflammatory genes in hepatocarcinomas }\end{array}$ \\
\hline DR2313 & Neuroprotectan \\
\hline EB-47.dihydrochloride.dihydrate & Antioxidant \\
\hline 4-Hydroxyquinazoline & Antioxidant \\
\hline 5-lodo-6-amino-1,2-benzopyrone & Neuroprotectan \\
\hline 1,5-Isoquinolinediol & Reduces repair of DNA damaged \\
\hline Minocycline hydrocloride & Anti-inflammatory and neuroprotectan \\
\hline Nicotinamide & Chemo- and radio-sensitizer \\
\hline NU1025 & Neuroprotectant \\
\hline 6(5H)-Phenanthridinone & Immunosuppressant \\
\hline \multicolumn{2}{|c|}{ PJ-34 [N-(6-oxo-5,6-dihydrophenanthridin-2-yl)- Anti-inflammatory } \\
\hline \multicolumn{2}{|l|}{$\mathrm{N}, \mathrm{N}$-dimethylacetamide. $\mathrm{HCl}]$} \\
\hline TIQ-A & Neuroprotectant \\
\hline
\end{tabular}

Table 4. A panel of PARP inhibitors 
The clinical experiences with PARP inhibitors are now focus on patients carrying mutations of the BRCA1 or BRCA2 genes, which have been linked to increased sensitivity to PARP-1 inhibitors. For example Olaparib has proved to be very efficient in patients with breast or ovarian cancer with germline mutations in these two genes [152-154]. Although mutations on BCRA2 mutations have a major impact on breast cancer growth, males carrying alteration on this gene also have a high risk of develop prostate cancer [153, 155]. Additional evidence has shown that impaired DNA repair might benefit from treatment with PARP inhibitors. In deed several evidences have proved that PARP inhibitors sensitize human prostate cancer cell lines [148, 149, 156]. It is also know that treatment with high doses of chemotherapy induces massive DNA damage leading to PARP-1 overactivation with the subsequent energy depletion and cell death of tumor cells that are highly resistant [157]. More recently, it was described that PARP-1 mediates the oncogenic EST transcription factor ERG, which is frequently observed in fusion to the androgen-regulated gene TMPRSS2 in a significant amount of prostate tumors [158]. PARP-1 inhibition (treatment with Olaparib) in this group of tumors increases expression of the ETS gene, which promotes accumulation of DNA damage. This study also demonstrated that ERG physically interacts with PARP-1 and DNA-PKCsPARP-1 and that PARP-1 has a critical role on ERG-mediated transition from high-grade prostatic intraepithelial neoplasia to invasive carcinoma [159]. These findings clearly showed that PARP-1 inhibition could potentially increase survival of patients with tumors ETS-positive. Interesting, Olaparib remained ineffective on tumors that did not show the gene fusion. Altogether this evidence support the enormous interest in stimulate the utilization of a new generation of relatively non-toxic, orally administered PARP inhibitors in a series of cancer in clinical trials to induce genomic instability and cell death, blocking the grow and spread of cancer cells. The fact that PARP inhibition is specific against prostate cancer cells is an exciting and promising therapy approach, in part, because they may cause less severe effects than traditional therapies or radiotherapy.

\section{Conclusion}

This review has highlighted the therapeutic potential of PARP inhibitors in prostate cancer as a monotherapy or in combination with another type therapy. PARP-1 is implicated in stabilizing the genomic content as well as in the selection of cells with unrepaired DNA damaged. A large body of evidence has demonstrated that inhibition of PARP-1 was sufficient to promote the development of tetraploidy in normal cells and effectively enhanced DNA damage in response to genotoxic agents. These results proved that the physical disruption of PARP-1 is essential for the maintenance of genomic instability. The increased expression of PARP-1 in a series of tumors has been related with cell proliferation and determination of the biological behavior of tumors, events that may predict the overall prognosis of the cancer. In this regard, studies on prostate cancer models in vitro and in vivo have shown that PARP inhibitions regulated the growth of tumors or prevented tumor invasion to other organs. Although several studies have provided promising results in treating advanced tumors, few clinical trials are available in prostate cancer, one of the most prevalent cancers 
affecting men. Indeed, PARP inhibitors are currently tested in breast cancer patients with mutations in the BRCA1 and BRCA2, which are also mutated in a significant number of prostate cancers. Since advanced prostate cancer generally develops resistance to chemotherapeutic and hormone therapies, the identification of mechanisms underlying prostate cancer progression is vital to identify potential targets for prostate cancer therapy. Recent findings have demonstrated that BRCA1 and BRCA2 mutations confer sensitivity to PARP inhibitors, promoting genomic instability and cell death, and that tumors with BRCA1 mutated are potential targets for a new generation of non-toxic PARP inhibitors. Moreover, the mechanism by which PARP-1 inhibition and BRCA mutations allow the accumulation of DNA errors and the promotion of tumor growth in prostate cells may provide the basis to develop more effective strategies for therapeutic intervention. However, the identification of new genetic markers are necessary to define the feasibility of PARP-1 as a therapeutically target for the treatment of patients with prostate cancer.

\section{Author details}

Luis A. Espinoza

Department of Biochemistry and Molecular \& Cell Biology, Georgetown University, Washington, DC, USA

\section{References}

[1] Morgentaler A 2006. Testosterone and prostate cancer: an historical perspective on a modern myth. Eur Urol 2006; 50(5): 935-9.

[2] Morgentaler A, Bruning CO, 3rd, DeWolf WC 1996. Occult prostate cancer in men with low serum testosterone levels. JAMA 1996; 276(23): 1904-6.

[3] Nishiyama T, Ikarashi T, Hashimoto Y, Suzuki K, Takahashi K 2006. Association between the dihydrotestosterone level in the prostate and prostate cancer aggressiveness using the Gleason score. J Urol 2006; 176(4 Pt 1): 1387-91.

[4] Mahler C, Denis L 1992. Management of relapsing disease in prostate cancer. Cancer 1992; 70(1 Suppl): 329-34.

[5] Chu KC, Tarone RE, Freeman HP 2003. Trends in prostate cancer mortality among black men and white men in the United States. Cancer 2003; 97(6): 1507-16.

[6] Odedina FT, Akinremi TO, Chinegwundoh F, Roberts R, Yu D, Reams RR, et al. 2009. Prostate cancer disparities in Black men of African descent: a comparative literature review of prostate cancer burden among Black men in the United States, Caribbean, United Kingdom, and West Africa. Infect Agent Cancer 2009; 4 Suppl 1(S2. 
[7] Abbott RR, Taylor DK, Barber K 1998. A comparison of prostate knowledge of African-American and Caucasian men: changes from prescreening baseline to postintervention. Cancer J Sci Am 1998; 4(3): 175-7.

[8] Chornokur G, Dalton K, Borysova ME, Kumar NB 2011. Disparities at presentation, diagnosis, treatment, and survival in African American men, affected by prostate cancer. Prostate 2011; 71(9): 985-97.

[9] Talcott JA, Spain P, Clark JA, Carpenter WR, Do YK, Hamilton RJ, et al. 2007. Hidden barriers between knowledge and behavior: the North Carolina prostate cancer screening and treatment experience. Cancer 2007; 109(8): 1599-606.

[10] McIntosh H 1997. Why do African-American men suffer more prostate cancer? J Natl Cancer Inst 1997; 89(3): 188-9.

[11] Jemal A, Siegel R, Ward E, Hao Y, Xu J, Thun MJ 2009. Cancer statistics, 2009. CA Cancer J Clin 2009; 59(4): 225-49.

[12] Trofimova I, Dimtchev A, Jung M, Rosenthal D, Smulson M, Dritschilo A, et al. 2002. Gene therapy for prostate cancer by targeting poly(ADP-ribose) polymerase. Cancer Res 2002; 62(23): 6879-83.

[13] Kummar S, Chen A, Parchment RE, Kinders RJ, Ji J, Tomaszewski JE, et al. 2012. Advances in using PARP inhibitors to treat cancer. BMC Med 2012; 10(25.

[14] Gradwohl G, Menissier de Murcia JM, Molinete M, Simonin F, Koken M, Hoeijmakers JH, et al. 1990. The second zinc-finger domain of poly(ADP-ribose) polymerase determines specificity for single-stranded breaks in DNA. Proc Natl Acad Sci U S A 1990; 87(8): 2990-4.

[15] Menissier-de Murcia J, Molinete M, Gradwohl G, Simonin F, de Murcia G 1989. Zincbinding domain of poly(ADP-ribose)polymerase participates in the recognition of single strand breaks on DNA. J Mol Biol 1989; 210(1): 229-33.

[16] Zaremba T, Ketzer P, Cole M, Coulthard S, Plummer ER, Curtin NJ 2009. Poly(ADPribose) polymerase-1 polymorphisms, expression and activity in selected human tumour cell lines. Br J Cancer 2009; 101(2): 256-62.

[17] Nosho K, Yamamoto H, Mikami M, Taniguchi H, Takahashi T, Adachi Y, et al. 2006. Overexpression of poly(ADP-ribose) polymerase-1 (PARP-1) in the early stage of colorectal carcinogenesis. Eur J Cancer 2006; 42(14): 2374-81.

[18] Shimizu M, Suzui M, Deguchi A, Lim JT, Xiao D, Hayes JH, et al. 2004. Synergistic effects of acyclic retinoid and OSI-461 on growth inhibition and gene expression in human hepatoma cells. Clin Cancer Res 2004; 10(19): 6710-21.

[19] Nomura F, Yaguchi M, Togawa A, Miyazaki M, Isobe K, Miyake M, et al. 2000. Enhancement of poly-adenosine diphosphate-ribosylation in human hepatocellular carcinoma. J Gastroenterol Hepatol 2000; 15(5): 529-35. 
[20] Hirai K, Ueda K, Hayaishi O 1983. Aberration of poly(adenosine diphosphate-ribose) metabolism in human colon adenomatous polyps and cancers. Cancer Res 1983; 43(7): 3441-6.

[21] Fukushima M, Kuzuya K, Ota K, Ikai K 1981. Poly(ADP-ribose) synthesis in human cervical cancer cell-diagnostic cytological usefulness. Cancer Lett 1981; 14(3): 227-36.

[22] Ikai K, Ueda K, Fukushima M, Nakamura T, Hayaishi O 1980. Poly(ADP-ribose) synthesis, a marker of granulocyte differentiation. Proc Natl Acad Sci U S A 1980; 77(6): 3682-5.

[23] Thomas C, Pfirrmann K, Pieles F, Bogumil A, Gillitzer R, Wiesner C, et al. 2012. Predictors for clinically relevant Gleason score upgrade in patients undergoing radical prostatectomy. BJU Int 2012; 109(2): 214-9.

[24] Alkhatib HM, Chen DF, Cherney B, Bhatia K, Notario V, Giri C, et al. 1987. Cloning and expression of cDNA for human poly(ADP-ribose) polymerase. Proc Natl Acad Sci U S A 1987; 84(5): 1224-8.

[25] Cherney BW, McBride OW, Chen DF, Alkhatib H, Bhatia K, Hensley P, et al. 1987. cDNA sequence, protein structure, and chromosomal location of the human gene for poly(ADP-ribose) polymerase. Proc Natl Acad Sci U S A 1987; 84(23): 8370-4.

[26] Schreiber V, Dantzer F, Ame JC, de Murcia G 2006. Poly(ADP-ribose): novel functions for an old molecule. Nat Rev Mol Cell Biol 2006; 7(7): 517-28.

[27] de Murcia G, Schreiber V, Molinete M, Saulier B, Poch O, Masson M, et al. 1994. Structure and function of poly(ADP-ribose) polymerase. Mol Cell Biochem 1994; 138(1-2): 15-24.

[28] El-Khamisy SF, Masutani M, Suzuki H, Caldecott KW 2003. A requirement for PARP-1 for the assembly or stability of XRCC1 nuclear foci at sites of oxidative DNA damage. Nucleic Acids Res 2003; 31(19): 5526-33.

[29] Bhatia K, Kang VH, Stein GS, Bustin M, Cherney BW, Notario V, et al. 1990. Cell cycle regulation of an exogenous human poly(ADP-ribose) polymerase cDNA introduced into murine cells. J Cell Physiol 1990; 144(2): 345-53.

[30] Hassa PO, Hottiger MO 2002. The functional role of poly(ADP-ribose)polymerase 1 as novel coactivator of NF-kappaB in inflammatory disorders. Cell Mol Life Sci 2002; 59(9): 1534-53.

[31] Kidwell WR, Mage MG 1976. Changes in poly(adenosine diphosphate-ribose) and poly(adenosine diphosphate-ribose) polymerase in synchronous HeLa cells. Biochemistry 1976; 15(6): 1213-7.

[32] Simbulan-Rosenthal CM, Rosenthal DS, Luo R, Samara R, Espinoza LA, Hassa PO, et al. 2003. PARP-1 binds E2F-1 independently of its DNA binding and catalytic domains, and acts as a novel coactivator of E2F-1-mediated transcription during re-entry of quiescent cells into S phase. Oncogene 2003; 22(52): 8460-71. 
[33] Espinoza LA, Crotti LB 2007. Roles of PARP-1 and p53 in the maintenance of genome integrity. Hauppauge, NY: Nova Science Publishers.

[34] Kasid UN, Halligan B, Liu LF, Dritschilo A, Smulson M 1989. Poly(ADP-ribose)mediated post-translational modification of chromatin-associated human topoisomerase I. Inhibitory effects on catalytic activity. J Biol Chem 1989; 264(31): 18687-92.

[35] Simbulan-Rosenthal CM, Rosenthal DS, Hilz H, Hickey R, Malkas L, Applegren N, et al. 1996. The expression of poly(ADP-ribose) polymerase during differentiationlinked DNA replication reveals that it is a component of the multiprotein DNA replication complex. Biochemistry 1996; 35(36): 11622-33.

[36] Baksi K, Alkhatib H, Smulson ME 1987. In vivo characterization of the poly(ADP-ribosylation) of SV40 chromatin and large T antigen by immunofractionation. Exp Cell Res 1987; 172(1): 110-23.

[37] Molinete M, Vermeulen W, Burkle A, Menissier-de Murcia J, Kupper JH, Hoeijmakers JH, et al. 1993. Overproduction of the poly(ADP-ribose) polymerase DNA-binding domain blocks alkylation-induced DNA repair synthesis in mammalian cells. Embo J 1993; 12(5): 2109-17.

[38] Dantzer F, de La Rubia G, Menissier-De Murcia J, Hostomsky Z, de Murcia G, Schreiber V 2000. Base excision repair is impaired in mammalian cells lacking Poly(ADP-ribose) polymerase-1. Biochemistry 2000; 39(25): 7559-69.

[39] Masson M, Niedergang C, Schreiber V, Muller S, Menissier-de Murcia J, de Murcia G 1998. XRCC1 is specifically associated with poly(ADP-ribose) polymerase and negatively regulates its activity following DNA damage. Mol Cell Biol 1998; 18(6): 3563-71.

[40] Vodenicharov MD, Sallmann FR, Satoh MS, Poirier GG 2000. Base excision repair is efficient in cells lacking poly(ADP-ribose) polymerase 1. Nucleic Acids Res 2000; 28(20): 3887-96.

[41] Kannan P, Yu Y, Wankhade S, Tainsky MA 1999. PolyADP-ribose polymerase is a coactivator for AP-2-mediated transcriptional activation. Nucleic Acids Res 1999; 27(3): 866-74.

[42] Kameoka M, Ota K, Tetsuka T, Tanaka Y, Itaya A, Okamoto T, et al. 2000. Evidence for regulation of NF-kappaB by poly(ADP-ribose) polymerase. Biochem J 2000; 346 Pt 3(641-9.

[43] Cervellera MN, Sala A 2000. Poly(ADP-ribose) polymerase is a B-MYB coactivator. J Biol Chem 2000; 275(14): 10692-6.

[44] Nie J, Sakamoto S, Song D, Qu Z, Ota K, Taniguchi T 1998. Interaction of Oct-1 and automodification domain of poly(ADP-ribose) synthetase. FEBS Lett 1998; 424(1-2): 27-32. 
[45] Ko L, Cardona GR, Chin WW 2000. Thyroid hormone receptor-binding protein, an LXXLL motif-containing protein, functions as a general coactivator. Proc Natl Acad Sci U S A 2000; 97(11): 6212-7.

[46] Butler AJ, Ordahl CP 1999. Poly(ADP-ribose) polymerase binds with transcription enhancer factor 1 to MCAT1 elements to regulate muscle-specific transcription. Mol Cell Biol 1999; 19(1): 296-306.

[47] Oei SL, Griesenbeck J, Schweiger M, Babich V, Kropotov A, Tomilin N 1997. Interaction of the transcription factor YY1 with human poly(ADP-ribosyl) transferase. Biochem Biophys Res Commun 1997; 240(1): 108-11.

[48] Ha HC, Hester LD, Snyder SH 2002. Poly(ADP-ribose) polymerase-1 dependence of stress-induced transcription factors and associated gene expression in glia. Proc Natl Acad Sci U S A 2002; 99(5): 3270-5.

[49] Chang WJ, Alvarez-Gonzalez R 2001. The sequence-specific DNA binding of NF-kappa $B$ is reversibly regulated by the automodification reaction of poly (ADP-ribose) polymerase 1. J Biol Chem 2001; 276(50): 47664-70.

[50] Hassa PO, Covic M, Hasan S, Imhof R, Hottiger MO 2001. The enzymatic and DNA binding activity of PARP-1 are not required for NF-kappa B coactivator function. J Biol Chem 2001; 276(49): 45588-97.

[51] Simbulan CM, Suzuki M, Izuta S, Sakurai T, Savoysky E, Kojima K, et al. 1993. Poly(ADP-ribose) polymerase stimulates DNA polymerase alpha by physical association. J Biol Chem 1993; 268(1): 93-9.

[52] Simbulan-Rosenthal CM, Rosenthal DS, Boulares AH, Hickey RJ, Malkas LH, Coll JM, et al. 1998. Regulation of the expression or recruitment of components of the DNA synthesome by poly(ADP-ribose) polymerase. Biochemistry 1998; 37(26): 9363-70.

[53] Meisterernst M, Stelzer G, Roeder RG 1997. Poly(ADP-ribose) polymerase enhances activator-dependent transcription in vitro. Proc Natl Acad Sci U S A 1997; 94(6): 2261-5.

[54] Oei SL, Griesenbeck J, Schweiger M, Ziegler M 1998. Regulation of RNA polymerase II-dependent transcription by poly(ADP-ribosyl)ation of transcription factors. J Biol Chem 1998; 273(48): 31644-7.

[55] Satoh MS, Lindahl T 1992. Role of poly(ADP-ribose) formation in DNA repair. Nature 1992; 356(6367): 356-8.

[56] Satoh MS, Poirier GG, Lindahl T 1993. NAD(+)-dependent repair of damaged DNA by human cell extracts. J Biol Chem 1993; 268(8): 5480-7.

[57] Yoshihara K, Itaya A, Tanaka Y, Ohashi Y, Ito K, Teraoka H, et al. 1985. Inhibition of DNA polymerase alpha, DNA polymerase beta, terminal deoxynucleotidyl transfer- 
ase, and DNA ligase II by poly(ADP-ribosyl)ation reaction in vitro. Biochem Biophys Res Commun 1985; 128(1): 61-7.

[58] Ikeguchi M, Saito H, Kondo A, Tsujitani S, Maeta M, Kaibara N 1999. Mutated p53 protein expression and proliferative activity in advanced gastric cancer. Hepatogastroenterology 1999; 46(28): 2648-53.

[59] Poirier GG, de Murcia G, Jongstra-Bilen J, Niedergang C, Mandel P 1982. Poly(ADPribosyl)ation of polynucleosomes causes relaxation of chromatin structure. Proc Natl Acad Sci U S A 1982; 79(11): 3423-7.

[60] Frechette A, Huletsky A, Aubin RJ, de Murcia G, Mandel P, Lord A, et al. 1985. Poly(ADP-ribosyl)ation of chromatin: kinetics of relaxation and its effect on chromatin solubility. Can J Biochem Cell Biol 1985; 63(7): 764-73.

[61] Wang ZQ, Auer B, Stingl L, Berghammer H, Haidacher D, Schweiger M, et al. 1995. Mice lacking ADPRT and poly(ADP-ribosyl)ation develop normally but are susceptible to skin disease. Genes Dev 1995; 9(5): 509-20.

[62] de Murcia JM, Niedergang C, Trucco C, Ricoul M, Dutrillaux B, Mark M, et al. 1997. Requirement of poly(ADP-ribose) polymerase in recovery from DNA damage in mice and in cells. Proc Natl Acad Sci U S A 1997; 94(14): 7303-7.

[63] Trucco C, Oliver FJ, de Murcia G, Menissier-de Murcia J 1998. DNA repair defect in poly(ADP-ribose) polymerase-deficient cell lines. Nucleic Acids Res 1998; 26(11): 2644-9.

[64] Masutani M, Nozaki T, Nishiyama E, Shimokawa T, Tachi Y, Suzuki H, et al. 1999. Function of poly(ADP-ribose) polymerase in response to DNA damage: gene-disruption study in mice. Mol Cell Biochem 1999; 193(1-2): 149-52.

[65] Ishizuka S, Martin K, Booth C, Potten CS, de Murcia G, Burkle A, et al. 2003. Poly(ADP-ribose) polymerase- 1 is a survival factor for radiation-exposed intestinal epithelial stem cells in vivo. Nucleic Acids Res 2003; 31(21): 6198-205.

[66] Wesierska-Gadek J, Schloffer D, Gueorguieva M, Uhl M, Skladanowski A 2004. Increased susceptibility of poly(ADP-ribose) polymerase-1 knockout cells to antitumor triazoloacridone C-1305 is associated with permanent G2 cell cycle arrest. Cancer Res 2004; 64(13): 4487-97.

[67] Potosky AL, Davis WW, Hoffman RM, Stanford JL, Stephenson RA, Penson DF, et al. 2004. Five-year outcomes after prostatectomy or radiotherapy for prostate cancer: the prostate cancer outcomes study. J Natl Cancer Inst 2004; 96(18): 1358-67.

[68] Hagan MP, Yacoub A, Dent P 2007. Radiation-induced PARP activation is enhanced through EGFR-ERK signaling. J Cell Biochem 2007; 101(6): 1384-93.

[69] Wollman R, Yahalom J, Maxy R, Pinto J, Fuks Z 1994. Effect of epidermal growth factor on the growth and radiation sensitivity of human breast cancer cells in vitro. Int $\mathrm{J}$ Radiat Oncol Biol Phys 1994; 30(1): 91-8. 
[70] Kimura K, Bowen C, Spiegel S, Gelmann EP 1999. Tumor necrosis factor-alpha sensitizes prostate cancer cells to gamma-irradiation-induced apoptosis. Cancer Res 1999; 59(7): 1606-14.

[71] Kimura K, Gelmann EP 2000. Tumor necrosis factor-alpha and Fas activate complementary Fas-associated death domain-dependent pathways that enhance apoptosis induced by gamma-irradiation. J Biol Chem 2000; 275(12): 8610-7.

[72] Aguero MF, Venero M, Brown DM, Smulson ME, Espinoza LA 2010. Phenoxodiol inhibits growth of metastatic prostate cancer cells. Prostate 2010; 70(11): 1211-21.

[73] Silasi DA, Alvero AB, Rutherford TJ, Brown D, Mor G 2009. Phenoxodiol: pharmacology and clinical experience in cancer monotherapy and in combination with chemotherapeutic drugs. Expert Opin Pharmacother 2009; 10(6): 1059-67.

[74] Alvero AB, O'Malley D, Brown D, Kelly G, Garg M, Chen W, et al. 2006. Molecular mechanism of phenoxodiol-induced apoptosis in ovarian carcinoma cells. Cancer 2006; 106(3): 599-608.

[75] Chen CD, Welsbie DS, Tran C, Baek SH, Chen R, Vessella R, et al. 2004. Molecular determinants of resistance to antiandrogen therapy. Nat Med 2004; 10(1): 33-9.

[76] Ide H, Yu J, Lu Y, China T, Kumamoto T, Koseki T, et al. 2011. Testosterone augments polyphenol-induced DNA damage response in prostate cancer cell line, LNCaP. Cancer Sci 2011; 102(2): 468-71.

[77] Yacoub A, Hawkins W, Hanna D, Young H, Park MA, Grant M, et al. 2007. Human chorionic gonadotropin modulates prostate cancer cell survival after irradiation or HMG CoA reductase inhibitor treatment. Mol Pharmacol 2007; 71(1): 259-75.

[78] Iwashita A, Tojo N, Matsuura S, Yamazaki S, Kamijo K, Ishida J, et al. 2004. A novel and potent poly(ADP-ribose) polymerase-1 inhibitor, FR247304 (5-chloro-2-[3-(4-phenyl-3,6-dihydro-1(2H)-pyridinyl)propyl]-4(3H)-quinazolinone), attenuates neuronal damage in in vitro and in vivo models of cerebral ischemia. J Pharmacol Exp Ther 2004; 310(2): 425-36.

[79] Fowler JE, Jr., Lau JL, Ghosh L, Mills SE, Mounzer A 1988. Epidermal growth factor and prostatic carcinoma: an immunohistochemical study. J Urol 1988; 139(4): 857-61.

[80] Yang Y, Chisholm GD, Habib FK 1993. Epidermal growth factor and transforming growth factor alpha concentrations in $\mathrm{BPH}$ and cancer of the prostate: their relationships with tissue androgen levels. Br J Cancer 1993; 67(1): 152-5.

[81] Connolly JM, Rose DP 1990. Production of epidermal growth factor and transforming growth factor-alpha by the androgen-responsive LNCaP human prostate cancer cell line. Prostate 1990; 16(3): 209-18.

[82] Connolly JM, Rose DP 1989. Secretion of epidermal growth factor and related polypeptides by the DU 145 human prostate cancer cell line. Prostate 1989; 15(2): 177-86. 
[83] Jarrard DF, Blitz BF, Smith RC, Patai BL, Rukstalis DB 1994. Effect of epidermal growth factor on prostate cancer cell line PC3 growth and invasion. Prostate 1994; 24(1): 46-53.

[84] Saadat M, Khalili M, Omidvari S, Ansari-Lari M 2011. Parental consanguineous marriages and clinical response to chemotherapy in locally advanced breast cancer patients. Cancer Lett 2011; 302(2): 109-12.

[85] Chen YL, Lin SZ, Chang JY, Cheng YL, Tsai NM, Chen SP, et al. 2006. In vitro and in vivo studies of a novel potential anticancer agent of isochaihulactone on human lung cancer A549 cells. Biochem Pharmacol 2006; 72(3): 308-19.

[86] Bieche I, de Murcia G, Lidereau R 1996. Poly(ADP-ribose) polymerase gene expression status and genomic instability in human breast cancer. Clin Cancer Res 1996; 2(7): 1163-7.

[87] Nguyen D, Zajac-Kaye M, Rubinstein L, Voeller D, Tomaszewski JE, Kummar S, et al. 2011. Poly(ADP-ribose) polymerase inhibition enhances p53-dependent and -independent DNA damage responses induced by DNA damaging agent. Cell Cycle 2011; 10(23): 4074-82.

[88] Chiu SC, Wang MJ, Yang HH, Chen SP, Huang SY, Chen YL, et al. 2011. Activation of NAG-1 via JNK signaling revealed an isochaihulactone-triggered cell death in human LNCaP prostate cancer cells. BMC Cancer 2011; 11(146.

[89] Mendoza-Alvarez H, Alvarez-Gonzalez R 2001. Regulation of p53 sequence-specific DNA-binding by covalent poly(ADP-ribosyl)ation. J Biol Chem 2001; 276(39): 36425-30.

[90] Ringer L, Sirajuddin P, Yenugonda VM, Ghosh A, Divito K, Trabosh V, et al. 2010. VMY-1-103, a dansylated analog of purvalanol B, induces caspase-3-dependent apoptosis in LNCaP prostate cancer cells. Cancer Biol Ther 2010; 10(4): 320-5.

[91] Oren M 1999. Regulation of the p53 tumor suppressor protein. J Biol Chem 1999; 274(51): 36031-4.

[92] Selivanova G, Wiman KG 1995. p53: a cell cycle regulator activated by DNA damage. Adv Cancer Res 1995; 66(143-80.

[93] Tong WM, Cortes U, Wang ZQ 2001. Poly(ADP-ribose) polymerase: a guardian angel protecting the genome and suppressing tumorigenesis. Biochim Biophys Acta 2001; 1552(1): 27-37.

[94] Schmid G, Wang ZQ, Wesierska-Gadek J 1999. Compensatory expression of p73 in PARP-deficient mouse fibroblasts as response to a reduced level of regularly spliced wild-type p53 protein. Biochem Biophys Res Commun 1999; 255(2): 399-405.

[95] Wang X, Ohnishi K, Takahashi A, Ohnishi T 1998. Poly(ADP-ribosyl)ation is required for p53-dependent signal transduction induced by radiation. Oncogene 1998; 17(22): 2819-25. 
[96] Mandir AS, Simbulan-Rosenthal CM, Poitras MF, Lumpkin JR, Dawson VL, Smulson $\mathrm{ME}$, et al. 2002. A novel in vivo post-translational modification of p53 by PARP-1 in MPTP-induced parkinsonism. J Neurochem 2002; 83(1): 186-92.

[97] Valenzuela MT, Guerrero R, Nunez MI, Ruiz De Almodovar JM, Sarker M, de Murcia $\mathrm{G}$, et al. 2002. PARP-1 modifies the effectiveness of p53-mediated DNA damage response. Oncogene 2002; 21(7): 1108-16.

[98] Wang ZQ, Stingl L, Morrison C, Jantsch M, Los M, Schulze-Osthoff K, et al. 1997. PARP is important for genomic stability but dispensable in apoptosis. Genes Dev 1997; 11(18): 2347-58.

[99] Al-Hajj M, Clarke MF 2004. Self-renewal and solid tumor stem cells. Oncogene 2004; 23(43): 7274-82.

[100] Mimeault M, Batra SK 2006. Recent advances on multiple tumorigenic cascades involved in prostatic cancer progression and targeting therapies. Carcinogenesis 2006; 27(1): $1-22$.

[101] Miller SJ, Lavker RM, Sun TT 2005. Interpreting epithelial cancer biology in the context of stem cells: tumor properties and therapeutic implications. Biochim Biophys Acta 2005; 1756(1): 25-52.

[102] Mimeault M, Batra SK 2007. Functions of tumorigenic and migrating cancer progenitor cells in cancer progression and metastasis and their therapeutic implications. Cancer Metastasis Rev 2007; 26(1): 203-14.

[103] Beachy PA, Karhadkar SS, Berman DM 2004. Tissue repair and stem cell renewal in carcinogenesis. Nature 2004; 432(7015): 324-31.

[104] Bapat SA, Mali AM, Koppikar CB, Kurrey NK 2005. Stem and progenitor-like cells contribute to the aggressive behavior of human epithelial ovarian cancer. Cancer Res 2005; 65(8): 3025-9.

[105] Sutherland RM 1988. Cell and environment interactions in tumor microregions: the multicell spheroid model. Science 1988; 240(4849): 177-84.

[106] Takagi A, Watanabe M, Ishii Y, Morita J, Hirokawa Y, Matsuzaki T, et al. 2007. Threedimensional cellular spheroid formation provides human prostate tumor cells with tissue-like features. Anticancer Res 2007; 27(1A): 45-53.

[107] Ponti D, Costa A, Zaffaroni N, Pratesi G, Petrangolini G, Coradini D, et al. 2005. Isolation and in vitro propagation of tumorigenic breast cancer cells with stem/progenitor cell properties. Cancer Res 2005; 65(13): 5506-11.

[108] Bao S, Wu Q, Li Z, Sathornsumetee S, Wang H, McLendon RE, et al. 2008. Targeting cancer stem cells through L1CAM suppresses glioma growth. Cancer Res 2008; 68(15): 6043-8. 
[109] Zhang K, Waxman DJ 2010. PC3 prostate tumor-initiating cells with molecular profile FAM65Bhigh/MFI2low/LEF1low increase tumor angiogenesis. Mol Cancer 2010; $9(319$.

[110] Yamazaki J, Mizukami T, Takizawa K, Kuramitsu M, Momose H, Masumi A, et al. 2009. Identification of cancer stem cells in a Tax-transgenic (Tax-Tg) mouse model of adult T-cell leukemia/lymphoma. Blood 2009; 114(13): 2709-20.

[111] Quintana E, Shackleton M, Sabel MS, Fullen DR, Johnson TM, Morrison SJ 2008. Efficient tumour formation by single human melanoma cells. Nature 2008; 456(7222): 593-8.

[112] Bisson I, Prowse DM 2009. WNT signaling regulates self-renewal and differentiation of prostate cancer cells with stem cell characteristics. Cell Res 2009; 19(6): 683-97.

[113] Patrawala L, Calhoun-Davis T, Schneider-Broussard R, Tang DG 2007. Hierarchical organization of prostate cancer cells in xenograft tumors: the CD44+alpha2beta1+ cell population is enriched in tumor-initiating cells. Cancer Res 2007; 67(14): 6796-805.

[114] Li H, Chen X, Calhoun-Davis T, Claypool K, Tang DG 2008. PC3 human prostate carcinoma cell holoclones contain self-renewing tumor-initiating cells. Cancer Res 2008; 68(6): 1820-5.

[115] Visvader JE, Lindeman GJ 2008. Cancer stem cells in solid tumours: accumulating evidence and unresolved questions. Nat Rev Cancer 2008; 8(10): 755-68.

[116] Guzman-Ramirez N, Voller M, Wetterwald A, Germann M, Cross NA, Rentsch CA, et al. 2009. In vitro propagation and characterization of neoplastic stem/progenitorlike cells from human prostate cancer tissue. Prostate 2009; 69(15): 1683-93.

[117] Rybak AP, He L, Kapoor A, Cutz JC, Tang D 2011. Characterization of sphere-propagating cells with stem-like properties from DU145 prostate cancer cells. Biochim Biophys Acta 2011; 1813(5): 683-94.

[118] Gunia S, May M, Koch S, Dietel M, Erbersdobler A 2009. Expression of CD44s in incidental prostate cancer is more strongly associated with Gleason scores on subsequent radical prostatectomies than conventional prognostic parameters. Pathobiology 2009; 76(6): 286-92.

[119] Hurt EM, Kawasaki BT, Klarmann GJ, Thomas SB, Farrar WL 2008. CD44+ CD24(-) prostate cells are early cancer progenitor/stem cells that provide a model for patients with poor prognosis. Br J Cancer 2008; 98(4): 756-65.

[120] Maitland NJ, Collins AT 2008. Prostate cancer stem cells: a new target for therapy. J Clin Oncol 2008; 26(17): 2862-70.

[121] Gurel B, Iwata T, Koh CM, Yegnasubramanian S, Nelson WG, De Marzo AM 2008. Molecular alterations in prostate cancer as diagnostic, prognostic, and therapeutic targets. Adv Anat Pathol 2008; 15(6): 319-31. 
[122] Schalken JA 2005. Validation of molecular targets in prostate cancer. BJU Int 2005; 96 Suppl 2(23-9.

[123] Mousses S, Wagner U, Chen Y, Kim JW, Bubendorf L, Bittner M, et al. 2001. Failure of hormone therapy in prostate cancer involves systematic restoration of androgen responsive genes and activation of rapamycin sensitive signaling. Oncogene 2001; 20(46): 6718-23.

[124] Flavin R, Zadra G, Loda M 2010. Metabolic alterations and targeted therapies in prostate cancer. J Pathol 2010.

[125] Flavin R, Zadra G, Loda M 2011. Metabolic alterations and targeted therapies in prostate cancer. J Pathol 2011; 223(2): 283-94.

[126] Niu Y, Chang TM, Yeh S, Ma WL, Wang YZ, Chang C 2010. Differential androgen receptor signals in different cells explain why androgen-deprivation therapy of prostate cancer fails. Oncogene 2010; 29(25): 3593-604.

[127] Saeki N, Gu J, Yoshida T, Wu X 2010. Prostate stem cell antigen: a Jekyll and Hyde molecule? Clin Cancer Res 2010; 16(14): 3533-8.

[128] Mellado B, Codony J, Ribal MJ, Visa L, Gascon P 2009. Molecular biology of androgen-independent prostate cancer: the role of the androgen receptor pathway. Clin Transl Oncol 2009; 11(1): 5-10.

[129] Wegiel B, Evans S, Hellsten R, Otterbein LE, Bjartell A, Persson JL 2010. Molecular pathways in the progression of hormone-independent and metastatic prostate cancer. Curr Cancer Drug Targets 2010; 10(4): 392-401.

[130] Malumbres M, Barbacid M 2009. Cell cycle, CDKs and cancer: a changing paradigm. Nat Rev Cancer 2009; 9(3): 153-66.

[131] McNealy T, Frey M, Trojan L, Knoll T, Alken P, Michel MS 2003. Intrinsic presence of poly (ADP-ribose) is significantly increased in malignant prostate compared to benign prostate cell lines. Anticancer Res 2003; 23(2B): 1473-8.

[132] Martin DS, Bertino JR, Koutcher JA 2000. ATP depletion + pyrimidine depletion can markedly enhance cancer therapy: fresh insight for a new approach. Cancer Res 2000; 60(24): 6776-83.

[133] Green DR, Reed JC 1998. Mitochondria and apoptosis. Science 1998; 281(5381): 1309-12.

[134] Ide H, Tokiwa S, Sakamaki K, Nishio K, Isotani S, Muto S, et al. 2010. Combined inhibitory effects of soy isoflavones and curcumin on the production of prostate-specific antigen. Prostate 2010; 70(10): 1127-33.

[135] Hall W, Christie M, Currow D 2005. Cannabinoids and cancer: causation, remediation, and palliation. Lancet Oncol 2005; 6(1): 35-42. 
[136] Sarfaraz S, Adhami VM, Syed DN, Afaq F, Mukhtar H 2008. Cannabinoids for cancer treatment: progress and promise. Cancer Res 2008; 68(2): 339-42.

[137] Sreevalsan S, Joseph S, Jutooru I, Chadalapaka G, Safe SH 2011. Induction of apoptosis by cannabinoids in prostate and colon cancer cells is phosphatase dependent. Anticancer Res 2011; 31(11): 3799-807.

[138] Thomas E, Gannon PO, Koumakpayi IH, Latour M, Mes-Masson A, Saad F, editors. Implication of PARP-1 expression in prostate cancer progression. ASCO; 2011: J Clin Oncol.

[139] Ding R, Pommier Y, Kang VH, Smulson M 1992. Depletion of poly(ADP-ribose) polymerase by antisense RNA expression results in a delay in DNA strand break rejoining. J Biol Chem 1992; 267(18): 12804-12.

[140] Burkle A, Heilbronn R, zur Hausen H 1990. Potentiation of carcinogen-induced methotrexate resistance and dihydrofolate reductase gene amplification by inhibitors of poly(adenosine diphosphate-ribose) polymerase. Cancer Res 1990; 50(18): 5756-60.

[141] Morgan WF, Cleaver JE 1982. 3-Aminobenzamide synergistically increases sisterchromatid exchanges in cells exposed to methyl methanesulfonate but not to ultraviolet light. Mutat Res 1982; 104(6): 361-6.

[142] Waldman AS, Waldman BC 1991. Stimulation of intrachromosomal homologous recombination in mammalian cells by an inhibitor of poly(ADP-ribosylation). Nucleic Acids Res 1991; 19(21): 5943-7.

[143] Simbulan-Rosenthal CM, Ly DH, Rosenthal DS, Konopka G, Luo R, Wang ZQ, et al. 2000. Misregulation of gene expression in primary fibroblasts lacking poly(ADP-ribose) polymerase. Proc Natl Acad Sci U S A 2000; 97(21): 11274-9.

[144] Chatterjee S, Berger SJ, Berger NA 1999. Poly(ADP-ribose) polymerase: a guardian of the genome that facilitates DNA repair by protecting against DNA recombination. Mol Cell Biochem 1999; 193(1-2): 23-30.

[145] Rojo F, Garcia-Parra J, Zazo S, Tusquets I, Ferrer-Lozano J, Menendez S, et al. 2012. Nuclear PARP-1 protein overexpression is associated with poor overall survival in early breast cancer. Ann Oncol 2012; 23(5): 1156-64.

[146] Horton JK, Stefanick DF, Wilson SH 2005. Involvement of poly(ADP-ribose) polymerase activity in regulating Chk1-dependent apoptotic cell death. DNA Repair (Amst) 2005; 4(10): 1111-20.

[147] Dantzer F, Giraud-Panis MJ, Jaco I, Ame JC, Schultz I, Blasco M, et al. 2004. Functional interaction between poly(ADP-Ribose) polymerase 2 (PARP-2) and TRF2: PARP activity negatively regulates TRF2. Mol Cell Biol 2004; 24(4): 1595-607.

[148] Durkacz BW, Omidiji O, Gray DA, Shall S 1980. (ADP-ribose)n participates in DNA excision repair. Nature 1980; 283(5747): 593-6. 
[149] Thraves P, Mossman KL, Brennan T, Dritschilo A 1985. Radiosensitization of human fibroblasts by 3-aminobenzamide: an inhibitor of poly(ADP-ribosylation). Radiat Res 1985; 104(2 Pt 1): 119-27.

[150] Brock WA, Milas L, Bergh S, Lo R, Szabo C, Mason KA 2004. Radiosensitization of human and rodent cell lines by INO-1001, a novel inhibitor of poly(ADP-ribose) polymerase. Cancer Lett 2004; 205(2): 155-60.

[151] Barreto-Andrade JC, Efimova EV, Mauceri HJ, Beckett MA, Sutton HG, Darga TE, et al. 2011. Response of human prostate cancer cells and tumors to combining PARP inhibition with ionizing radiation. Mol Cancer Ther 2011; 10(7): 1185-93.

[152] Audeh MW, Carmichael J, Penson RT, Friedlander M, Powell B, Bell-McGuinn KM, et al. 2010. Oral poly(ADP-ribose) polymerase inhibitor olaparib in patients with BRCA1 or BRCA2 mutations and recurrent ovarian cancer: a proof-of-concept trial. Lancet 2010; 376(9737): 245-51.

[153] Fong PC, Boss DS, Yap TA, Tutt A, Wu P, Mergui-Roelvink M, et al. 2009. Inhibition of poly(ADP-ribose) polymerase in tumors from BRCA mutation carriers. N Engl J Med 2009; 361(2): 123-34.

[154] Tutt A, Robson M, Garber JE, Domchek SM, Audeh MW, Weitzel JN, et al. 2010. Oral poly(ADP-ribose) polymerase inhibitor olaparib in patients with BRCA1 or BRCA2 mutations and advanced breast cancer: a proof-of-concept trial. Lancet 2010; 376(9737): 235-44.

[155] Yap TA, Sandhu SK, Carden CP, de Bono JS 2011. Poly(ADP-ribose) polymerase (PARP) inhibitors: Exploiting a synthetic lethal strategy in the clinic. CA Cancer J Clin 2011; 61(1): 31-49.

[156] Liu SK, Coackley C, Krause M, Jalali F, Chan N, Bristow RG 2008. A novel poly(ADP-ribose) polymerase inhibitor, ABT-888, radiosensitizes malignant human cell lines under hypoxia. Radiother Oncol 2008; 88(2): 258-68.

[157] Mueller T, Voigt W, Simon H, Fruehauf A, Bulankin A, Grothey A, et al. 2003. Failure of activation of caspase-9 induces a higher threshold for apoptosis and cisplatin resistance in testicular cancer. Cancer Res 2003; 63(2): 513-21.

[158] Brenner JC, Chinnaiyan AM 2009. Translocations in epithelial cancers. Biochim Biophys Acta 2009; 1796(2): 201-15.

[159] Brenner JC, Ateeq B, Li Y, Yocum AK, Cao Q, Asangani IA, et al. 2011. Mechanistic rationale for inhibition of poly(ADP-ribose) polymerase in ETS gene fusion-positive prostate cancer. Cancer Cell 2011; 19(5): 664-78. 
